\title{
BEST MANAGEMENT CONTROL SYSTEMS AND FIRM EXCELLENCE: ELECTRICAL APPLIANCES AND ELECTRONIC PARTS BUSINESSES IN THAILAND
}

Chonthicha Thammavinyu, Mahasarakham Business School Mahasarakham University, Thailand Phapruke Ussahawanitchakit, Mahasarakham Business School Mahasarakham University, Thailand

dx.doi.org/10.18374//JBS-13-3.10

\begin{abstract}
This study develops the holistic view of management control systems (MCS) and its purpose is to investigate the relationship between antecedents of best MCS and firm excellence. The dimensions of best MCS are focused on cost management efficiency, budgeting preparation effectiveness, performance evaluation quality, and environmental awareness orientation. Theories used to develop the conceptual framework are Resource-Advantage Theory, Agency Theory, and Contingency Theory. Data were collected from 199 electrical appliances and electronic parts firms in Thailand by questionnaire mail survey. The ordinary least square regression is the statistical model used to test the hypotheses. The results suggest that budgeting preparation effectiveness has a direct positive effect on firm excellence, accounting system quality and employee involvement have a significant positive influence to best MCS. Further, accounting knowledge is a moderator of top management support and best MCS. Contributions and directions for future research are highlighted.
\end{abstract}

Keywords: Best Management Control Systems, Cost Management Efficiency, Budgeting Preparation Effectiveness, Performance Evaluation Quality, Environmental Awareness Orientation, Business Goal Achievement, Firm Excellence 